\title{
KIRMEIER, Josef, SCHNEIDMÜLLER, Bernd, WEINFURTER, Stefan, BROCKHOFF, Evamaria, Kaiser Heinrich II. 1002-1024
}

Pierre Monnet

\section{(2) OpenEdition \\ Journals}

Édition électronique

URL : http://journals.openedition.org/ifha/1167

DOI : 10.4000/ifha. 1167

ISSN : 2198-8943

Éditeur

IFRA - Institut franco-allemand (sciences historiques et sociales)

Référence électronique

Pierre Monnet, « KIRMEIER, Josef, SCHNEIDMÜLLER, Bernd, WEINFURTER, Stefan, BROCKHOFF, Evamaria, Kaiser Heinrich II. 1002-1024 », Revue de I'IFHA [En ligne], Date de recension, mis en ligne le 01 janvier 2002, consulté le 22 septembre 2020. URL : http://journals.openedition.org/ifha/1167 ; DOI : https://doi.org/10.4000/ifha. 1167

Ce document a été généré automatiquement le 22 septembre 2020.

(CIFHA 


\title{
KIRMEIER, Josef, SCHNEIDMÜLLER, Bernd, WEINFURTER, Stefan, BROCKHOFF, Evamaria, Kaiser Heinrich II. 1002-1024
}

\author{
Pierre Monnet
}

1 Depuis des décennies les Allemands ont pris l'habitude de marquer les anniversaires de leurs souverains et de leurs dynasties du Moyen Âge par de grandes expositions régionales. Après les Staufen (Stuttgart, 1977), les Wittelsbach (Landshut, 1980), les Zähringer (Fribourg, 1986), les Saliens (Spire, 1992), les Welfes (Brunswick, 1995), les Francs (Mannheim, 1997), les Alamans (Stuttgart/ Zürich/ Augsbourg, 1997-1998), les Carolingiens (Paderborn, 1999), les Ottoniens (Magdebourg, 2001, voir dans le présent Bulletin l'article bibliographique sur l'année ottonienne), c'est au tour de Henri II, couronné le 7 juin 1002, de voir son millénaire célébré par une exposition qui, du 9 juillet au 20 octobre 2002 associe une ville, une université et une région : Bamberg et la Bavière, Bamberg en raison de la fondation de cet évêché par le roi en 1007, et la Bavière parce que pour la première fois un duc de cette principauté accédait au trône germanique le 7 juin 1002 avant de devenir empereur en 1014. Pour ces motifs, il y a tout lieu de penser que, comme les précédentes, cette manifestation sera un succès public. Car Henri II fut successivement duc, roi, empereur et saint. C'est d'ailleurs le seul souverain à avoir été canonisé conjointement à son épouse Cunégonde de Luxembourg et le couple fit l'objet d'un culte dans plusieurs diocèses, à Bamberg naturellement, mais aussi à Paderborn et à Mersebourg. Pour autant, la mémoire royale de Henri II n'a pas en Allemagne l'aura de celle d'un Charlemagne, d'Otton le Grand ou de Frédéric Barberousse.

L'exposition, accompagnée d'un riche catalogue (augmenté sur commande d'un CDRom opérant une visite virtuelle) et présentée dans plusieurs lieux de la ville (Musée diocésain, Musée historique, cathédrale et bibliothèque d'État), entend donc réparer cette injustice et surtout présenter à un large public l'état de la recherche sur un grand 
roi, sur sa cour, sur l'Église de l'Empire et la culture de son royaume pendant les premières décennies du nouveau millénaire. Le roi d'abord, figure emblématique de la grandeur et du tragique de la royauté impériale en Allemagne : il porta haut la symbolique impériale mais demeura sans héritier mâle. Roi-prêtre et roi-évêque, il fut à la tête d'une sorte de collège épiscopal étendu aux limites connues de l'Empire qu'il ne cessa d'arpenter de cathédrales en palais, combla les églises et les grands clercs d'objets, de fondations, de reliques et de manuscrits richement enluminés. Nul doute que ce roi pensait déjà à sa postérité, à une memoria royale qui pourrait aboutir à la sainteté dont le culte demeura orchestré et établi dans la ville chérie de Bamberg. Il n'est donc pas étonnant de voir en introduction au catalogue les cinq articles signés par des médiévistes de renom insister sur la personne royale et son lien indéfectible à la cité de Bamberg, image d'une relation entre un roi et son Église que la Querelle des Investitures n'était pas encore venue déchirer.

Comme il se doit, finissons cette incursion dans un grand règne par l'image la plus connue du Moyen Âge allemand, celle du cavalier de Bamberg placé dans la partie occidentale de l'entrée nord du chœur, figure si imposante qu'elle clôt le catalogue des 215 objets recensés. Cette statue, réalisée vers 1225 , représenterait selon les dernières interprétations le saint roi Stéphane de Hongrie (997-1038), beau-frère d'Henri II, et était orientée de telle sorte que le regard du cavalier désignât les tombes royales du saint couple Henri et Cunégonde. Le visiteur demeure frappé par le port du cavalier, la profondeur de son regard, l'aura de la sainteté royale. Il est agréable de penser que cette statue demeurera longtemps après la fin des fastes de l'exposition. 